BULLETIN Bulletin hispanique

HISPANIQUE

Université Michel de Montaigne Bordeaux

116-2 | 2014

Référentialité/autoréférentialité dans le roman espagnol contemporain : bilan et perspectives

\title{
Los cuentos de Javier Marías
}

la técnica del detalle

\section{Fernando Valls}

\section{(2) OpenEdition}

Journals

\section{Edición electrónica}

URL: http://journals.openedition.org/bulletinhispanique/3405

DOI: 10.4000/bulletinhispanique.3405

ISBN: 979-10-300-0156-3

ISSN: 1775-3821

\section{Editor}

Presses universitaires de Bordeaux

\section{Edición impresa}

Fecha de publicación: 1 diciembre 2014

Paginación: 571-591

ISBN: 978-2-86781-963-6

ISSN: 0007-4640

Referencia electrónica

Fernando Valls, "Los cuentos de Javier Marías », Bulletin hispanique [En línea], 116-2 | 2014, Publicado el 01 diciembre 2017, consultado el 02 mayo 2019. URL : http://journals.openedition.org/

bulletinhispanique/3405; DOI : 10.4000/bulletinhispanique.3405 


\title{
Los cuentos de Javier Marías: la técnica del detalle
}

\author{
FERNANDo VAlLS \\ Universidad Autónoma de Barcelona
}

Para Geneviève Champeau, en Burdeos, maestra de hispanistas

Cet article propose le commentaire de cinq nouvelles de Javier Marias, afin de mettre en évidence leurs ressemblances et leurs différences, tout en les reliant à son cuvre narrative et à ses essais : sil existait chez Marias une nouvelle-typelexemplaire, son narrateur s'attacherait à transmettre l'histoire qu'il a entendue ou qu'on lui a racontée. Centrées sur le détail, ses nouvelles, plutôt que filles de ses romans, partagent avec eux le même univers narratif.

Mots-clés: nouvelle, détail, transmission.

Se comentan cinco relatos de Javier Marias, intentando poner de manifiesto similitudes $y$ diferencias, relacionándolos con el resto de su obra narrativa y ensayistica, pues de existir un cuento tipo de Marías, el narrador sería alguien ansioso por transmitir la peripecia que ha oido o que le han contado. Sustentados en el detalle, más que ser hijos de sus novelas comparten un mundo narrativo semejante.

Palabras clave: relato, detalle, transmitir.

This paper comments five short stories by Javier Marias in order to show their similarities and differences, while relating them with his novels and essays. If such a thing as a type of short story exists in Marias' works, we could say that its narrator is someone who wants to transmit the story he's heard or he's been told. Focused on details, Marias' short stories share their narrative universe with his novels.

Keywords: short story, detail, transmission. 
En el arte elevado y en la ciencia pura el detalle lo es todo.

De Vladimir Nabokov a Javier Marías ${ }^{1}$

$\mathrm{E}$ 1 primer texto literario que publicó Javier Marías (Madrid, 1951), cuando solo tenía 17 años aunque lo había escrito con 14, como él mismo ha precisado, fue un cuento en el que se ocupaba de lo escatológico y sobrenatural, "La vida y la muerte de Marcelino Iturriaga», aparecido en El Noticiero Universal (el 19 de abril de 1968), diario de Barcelona que ya no existe. Ese primitivo relato remite a "Cuando fui mortal» ${ }^{2}$, si bien tuvieron que pasar bastantes años antes de que publicara su primer libro de cuentos, Mientras ellas duermen (1990), cuando ya tenía en su haber seis novelas: de Los dominios del lobo (1971) a Todas las almas (1989). Las piezas que lo componen habían aparecido en diarios, revistas y antologías, o en el volumen colectivo titulado Tres cuentos didácticos (1975), donde se recoge «La dimisión de Santiesteban». Así, durante los últimos años ochenta y primeros noventa empieza a consolidarse en España una nueva hornada de cultivadores de la narrativa breve, con libros de autores tan dispares, en edad y estética -recuerdo solo los más destacados-, como Las otras vidas (1988) y Nada del otro mundo (1993), de Antonio Muńoz Molina; El sabor del viento (1988), de Ramón Gil Novales; La tierra será un paraíso (1989) y Misterios de las noches y los días (1992), de Juan Eduardo Zúñiga; Brasas de agosto (1989), de Luis Mateo Díez; Perros verdes (1989) y Escaleras en el limbo (1991), de Agustín Cerezales; El viajero perdido (1990), de José María Merino; El ángulo del horror (1990), de Cristina Fernández Cubas; Cuentos de Bloomsbury (1991), de Ana María Navales; Suicidios ejemplares (1991) e Hijos sin hijos (1993), de Enrique Vila-Matas; Primavera de luto y otros cuentos (1992), de Juan José Millás; y Extranjeros en la noche (1992), de Antonio Soler. Y de un año después, de 1993, datan las antologías de Ángeles Encinar y Anthony Percival, la inglesa de Masoliver Ródenas y la mía ${ }^{3}$.

Javier Marías ha repetido en más de una ocasión que el cuento forma parte de una tradición narrativa distinta de la novela, puesto que no solo se diferencia de ella por su extensión, sino que exige también una intensidad continua que no precisa la narrativa más extensa, que permite altibajos, dado que estos forman parte de su respiración natural. Pero, además, el cuento debe contener una historia, tensión y una cierta singularidad, así como generar inquietud, y no limitarse a reproducir únicamente los estados de ánimo de los personajes. Para nuestro autor, la tradición del cuento en Espańa ha sido pobre, sobre todo si la

1. La frase de Nabokov la recuerda Marías en su artículo "Las patas del perro», Literatura y fantasma, 2000, p. 349. Cito siempre por esta edición ampliada. Para las referencias completas, vid. el listado bibliográfico final.

2. Vid. «Contar el misterio», Literatura y fantasma, p. 117.

3. Vid. Ángeles Encinar y Anthony Percival, eds., Cuento español contemporáneo, Cátedra, Madrid, 1993; Juan Antonio Masoliver Ródenas, ed., The Origin of Desire. Modern Spanish Short Stories, Serpent's Tail, Londres, 1993, y Fernando Valls, ed., Son cuentos. Antología del relato breve español. 1975-1993, Espasa Calpe (Austral, 326), Madrid, 1993. 
comparamos con la inglesa o con la hispanoamericana. Por ello reconoce sentirse cercano a Borges, quizás al formar parte de una estirpe literaria que proviene de Poe y Kipling, cuyo «El hombre que iba a ser rey» parece que era el cuento favorito de Proust y Faulkner, y probablemente también uno de los preferidos de nuestro autor ${ }^{4}$. De igual modo, Marías considera a Isak Dinesen una de las mejores escritoras de relatos del siglo XX, «el hilo de la continuidad de todos los cuentos, desde Las mil y una noches en adelante" ${ }^{5}$; ha elogiado cuentos de Joyce como "Los muertos», o "Todos los pilotos muertos», de Faulkner ${ }^{6}$; aunque también ha mostrado su interés por los Nueve cuentos (1953), de J. D. Salinger, de quien tradujo tres piezas, y por los de Raymond Carver, no así por los de sus miméticos e innumerables continuadores. Tampoco se muestra partidario de los cuentos arábigos, en los que el desenlace suele depender de la frase final ${ }^{7}$.

Nuestro autor suele utilizar cuento y relato como sinónimos, aunque en el subtítulo de sus cuentos [escogidos] completos se haya decantado por el concepto de cuento. Hasta donde yo sé, creo que no ha llegado a teorizar sobre el género, al menos de manera sistemática, pero podría decirse que, en cierta forma, lo ha hecho cuando se ha ocupado de los autores que aprecia, como Dinesen o Salinger. En cambio, sí se ha planteado, en breves comentarios, la relación que mantiene el cuento con la novela o la importancia de los cuentos de género.

El caso es que Javier Marías nunca ha concebido un libro de cuentos como tal, digamos, con una cierta unidad interna, sino que se ha limitado a publicar piezas acumuladas a lo largo de los años, dándole al conjunto el título de uno de ellos, de entre los que consideraba mejores. Así, a los dos libros de relatos publicados por el autor, habría que añadir sus recientes cuentos «aceptados y aceptables», titulados mediante el mismo procedimiento, Mala indole. Tres características de diversa entidad los singularizan. Primera, muchas de estas narraciones, aparecidas primero en diarios y revistas, son el resultado de un encargo, con sus correspondientes imposiciones de espacio, para ajustarse a unas páginas determinadas, o temáticas, bien como cuentos de verano, de fútbol, madrileños, etc. A él le gusta recordar que esto no debería extrañarnos, habida cuenta de que algunas piezas maestras de la historia de la música, diversos cuadros, y no menos películas inolvidables también surgieron de este modo. Segunda, varios de ellos han sido retocados en diversas reimpresiones. $\mathrm{Y}$ tercera, tienen en común el trasvase de géneros: del artículo al cuento («Lo que dijo el mayordomo», "Todo mal vuelve» o «No más amores»), del relato

4. Vid. «Rudyard Kipling sin bromas», Vidas escritas, 2012, p. 156. Recuérdese también la célebre película de John Huston, The Men Who Would Be King (El hombre que pudo reinar) (1975), basada en el citado cuento, protagonizada por Sean Connery y Michael Caine.

5. Vid. «La memoria locuaz leída», A veces un caballero, p. 357.

6. Vid. «De memoria locuaz leída», A veces un caballero, p. 356; $\mathrm{y}$ «Todos los actores muertos», Donde todo ha sucedido. Al salir del cine, p. 122.

7. Entre los libros de narraciones traducidos por Marías figuran los siguientes: El brazo marchito y otros relatos, de Thomas Hardy, cuya primera versión data de 1974, aunque luego aparecieron en la Editorial Reino de Redonda, en el 2004; la antología Cuentos únicos (1987), buena prueba de su interés por los relatos de miedo, de fantasmas; y varios cuentos de J.D. Salinger. 
a la novela, más o menos ampliados («En el viaje de novios» y Corazón tan blanco); la relación entre cuento y novela («Un epigrama de lealtad» y Todas las almas) o la adaptación, como la sufrida por «Serán nostalgias» respecto a «No más amores», prueba de que el mismo relato puede contarse varias veces con distintas palabras. Por último, otros se han ido gestando a la par, compartiendo elementos: tal sucede en "Cuando fui mortal» y Mañana en la batalla piensa en mi. Así, podría afirmarse que artículos, cuentos, miramientos y novelas se hallan intrínsecamente relacionados, aunque habría que estudiar de qué forma se producen estos trasvases intergenéricos ${ }^{8}$.

En esta ocasión voy a centrar el análisis en cinco relatos: «Mientras ellas duermen», «Domingo de carne», «Un sentido de camaradería», «Mala índole» y el primitivo «El viejo vasco-andaluz», intentando poner de manifiesto sus similitudes y diferencias?. ¿Por qué los he elegido? En el caso del primero, porque me parece uno de sus mejores cuentos, y porque en esas páginas encontramos varios de los temas, motivos y mecanismos representativos del conjunto de la obra de Marías. Así, por ejemplo, el relato empieza siendo una cosa, para concluir siendo otra completamente distinta. Algo semejante ocurre también en «Mala índole». El segundo cuento citado es hermano mellizo del primero, como veremos, mientras que el tercero comparte el recurso de la confesión. Y respecto al último, lo he escogido porque se trata de una pieza tan temprana como desconocida en la que encontramos en esbozo algunas de las características de su obra posterior, de madurez.

«Mientras ellas duermen» está dedicado a Daniella Pittarello, seguramente una de las mayores expertas en la obra de Marías: la profesora italiana Elide Pittarello, de la Universidad de Venecia, a quien también le dedica Vida del fantasma (2001), por ser una de «las bien queridas», junto a Carmen [GarcíaMallo], Julia [Altares], Mercedes [López Ballesteros] y Carme [López M.] ${ }^{10}$. Lo que relata el narrador en primera persona, cuando los hechos ya han transcurrido y se ha puesto a escribirlos, como aclara en un par de ocasiones (p. 86 y 95), es el encuentro -fruto del azar, la curiosidad y el insomnio- de dos parejas en una playa en Menorca cercana a Fornells, en una isla, se insiste, «la isla perdida de ingleses», durante unas vacaciones de tres semanas (p. 80, 94 y 99). O para ser más precisos, cómo el innominado narrador y Luisa ${ }^{11}$,

8. Vid., al respecto, mi artículo "Lo que dijo el mayordomo", de Javier Marías, o la disolución de los géneros literarios narrativos», en Irene Andres-Suárez, ed., Mestizaje y disolución de géneros en la narrativa hispánica contemporánea.

9. En trabajos citados en la bibliografía final me he ocupado con un cierto detenimiento de otros cuentos del autor, como «La dimisión de Santiesteban», «Lo que dijo el mayordomo», «El médico nocturno», «Cuando fui mortal», «Todo mal vuelve» y «No más amores». Las páginas de los cuentos en los que centro mi comentario remiten a la reciente antología: Mala indole. Cuentos aceptados y aceptables.

10. Sobre las dedicatorias de sus libros, vid. lo que comenta el autor en "Novelas cifradas», Mano de sombra, p. 280-282. Entre las dos ediciones de Vida del fantasma, la de 1995, en Alfaguara, y la titulada Vida del fantasma. Cinco años más tenue, del 2000, se añade el nombre de Carme en la dedicatoria.

11. Vid. lo que escribe José María Pozuelo Yvancos sobre estos narradores innominados, 
su esposa, se fijan en una pareja singular, compuesta por Alberto Viana e Inés, mucho más joven; y la posterior conversación nocturna al borde de la piscina entre ambos hombres, que no es más que la confesión de Viana en respuesta a las preguntas que le formula el narrador. Las dos parejas están fuera de su entorno habitual de vida y trabajo, en espacios neutrales, en cierta forma lo que ahora llamamos no lugares, y quizás ello, el hecho de que coincida con el último día de vacaciones de la desigual pareja, propicie la confidencia. Como tantos otros narradores de Marías, éste también es un testigo más o menos pasivo, que se limita a observar, indagar y transmitir, según él mismo apunta: «la mejor manera de no participar en la charla era no decir nada, comportarme como mero depositario de sus confidencias, sin objetar y sin aconsejar, sin rebatir ni asentir ni escandalizarme» (p. 101). Pero conforme avanza la conversación, su actitud va cambiando, pues empieza a inquietarse por el rumbo que esta cobra.

Destaca que aquello que empieza siendo en el cuento meramente curioso, anecdótico o pintoresco, a medida que progresa la confesión de Viana, vaya convirtiéndose en sorprendente, inquietante e incluso trágico. Así, podría decirse que el relato se compone de tres partes diferenciadas. En la primera (p. 79-81) se cuenta cómo durante unas vacaciones en la playa, el narrador y Luisa se fijan en los movimientos más peculiares de algunos bañistas: un niñito, "un marinerito italiano» amigo de llevar a cabo hazañas al borde del agua; un inglés despótico de mediana edad; y la citada pareja, de conducta más que singular, formada por un hombre maduro, calvo y rechoncho, y una joven atractiva. De todos ellos, quienes más consiguen despertar su curiosidad son estos últimos, quizá por tratarse del comportamiento más insólito y, sobre todo, porque ambos pueden esconder la historia más interesante, como se confirmará más adelante, aunque nada más volvamos a saber ni del niñito ni del señor inglés. En cambio, a Viana no le interesa lo que ocurre en la playa, pues su atención se centra exclusivamente en Inés, aunque reconoce al narrador cuando se encuentran en la piscina, durante la noche.

La segunda parte (p. 81-86) se ciñe a la descripción de la pareja, en la extraña relación que parecen mantener, pues él no deja de filmarla, mientras que ella toma el sol y pule su cuerpo de cualquier presencia molesta, ya sea en forma de pelo o protuberancia de la piel. La filma constantemente porque -apunta"quiero tener guardado su último día», puesto que "es importante el último día en la vida de una persona», una variante de las «últimas palabras» que se pronuncian antes de morir (p. 93). Y en la tercera, mucho más extensa (p. 87104), quien narra pone por escrito la historia, el diálogo que ambos hombres mantuvieron, mientras presumiblemente las dos mujeres duermen, la confesión que le hizo Viana. Aquí, desde el momento en que el narrador abandona su

Figuraciones del yo en la narrativa: Javier Marías y Enrique Vila-Matas, p. 57-62. El nombre de Luisa, frecuente en las ficciones de Marías, lo lleva también la protagonista de Corazón tan blanco; la mujer del narrador de Todas las almas y Tu rostro mañana, pues se trata del mismo personaje; la viuda de Desvern en Los enamoramientos; las esposas de los narradores de los cuentos «Domingo de carne» $\mathrm{y}$ "Cuando fui mortal»; y la hermana de Marta Téllez, en Mañana en la batalla piensa en mí. Vid. Pittarello, ed., Corazón tan blanco, p. 111, nota 1. 
habitación y hasta el desenlace, el tiempo parece abolido, la débil rueda del mundo - metáfora habitual del autor-, detenida («no había mirado la hora», «me había dejado el reloj arriba», "no tenía reloj» y «no tenía reloj, cuánto había durado», comenta este hasta en cuatro ocasiones), pues ellas duermen, y quizá también imaginen, mientras «el portero de noche -se afirma- soñaba incómodamente con la cabeza sobre su mostrador, como un futuro decapitado» (p. 88, 92, 99 y 104). Si bien en la primera y en la segunda parte conocemos a los protagonistas, en la tercera se muestran casi todas las cartas en juego: las intenciones de Viana y la consiguiente inquietud del narrador.

El desenlace se presenta abierto, pues aparte de no desentrańarse el misterio, esto es, la historia de los peculiares vínculos que unen a Viana e Inés (él insiste en que su relación con la joven nunca fue "normal» sino "extraordinaria», p. 94), el asunto queda aún más oscuro tras la confesión, ya que solo se nos explican los aspectos anecdóticos de la relación, junto con la «lógica estricta» de la conducta y las expectativas de Viana, que no resulta precisamente ortodoxa. Por otro lado, en el desenlace se plantea un enigma sin resolver, que se apuntaba en las dos primeras frases del cuento. Mediante su declaración, Viana hace partícipe de la historia al narrador, de quien podría decirse -como les ocurre a tantos otros personajes de nuestro autor, baste recordar las primeras líneas de Corazón tan blanco- que quería saber, pero no lo que le han contado, porque supera su curiosidad, de ahí que en un momento dado desee concluir el diálogo a la vista del rumbo que ha ido cobrando. Aquello que ha oído no conseguirá olvidarlo y acabará escribiéndolo, como sabemos. Sin embargo, no encuentra el momento adecuado para despedirse hasta que Luisa lo rescata, haciéndole una seña desde la terraza de la habitación. Lo singular de este diálogo estriba en la contraposición de dos lógicas distintas: la racional del narrador, quien va formulando las preguntas que probablemente se esté planteando el lector, y la «lógica estricta» (p. 97 y 101), aunque me temo que perversa, empleada por Viana, con sus sinrazones.

Tres son los espacios, todos ellos significativos, por los que transcurre la breve acción. La primera y la segunda parte se desarrollan en la playa, con el sombrero de paja visivo y la cámara de Viana como objetos protagonistas ${ }^{12}$; mientras que la última parte arranca en la habitación que comparten Luisa y su marido, con la terraza como espacio revelador ${ }^{13}$, y concluye en la piscina del hotel en el que se hospedan ambas parejas, con la luna, los mocasines, las tumbonas (una floreada y la otra a rayas) y el calcetín mojado, goteante, como detalles significativos; el lugar en que conversan los dos hombres, también de la confesión, de la ¿̇aclaración? del caso. Pero, por lo que respecta al narrador, ya se halle este en la habitación, ya coincida con el momento de bajar a la

12. Podría añadirse también, aunque tengan mucho menos protagonismo, el gorrito de marinero del niño y la camiseta verde del bañista inglés, a quienes observan en la playa.

13. Desempeńa una función semejante en «Domingo de carne», como veremos, «En el viaje de novios» y en la novela Corazón tan blanco. 
piscina, la terraza se convierte en un punto de referencia importante, bien sea para observar desde el balcón, bien para otearla desde abajo, buscando algo de esperanza en su creciente malestar.

Durante su charla, ambos hombres establecen diferencias primero entre ver y mirar, después entre recordar y ver, y finalmente el narrador afirma que "fijar la vista [en los pies o en el calcetín anegado] era una manera de engañar el oído» (p. 85, 91 y 96). Debe tenerse en cuenta, de igual modo, que los personajes se valen de mediaciones para observar a los demás, e incluso a sí mismos. Luisa mira en la playa a través del sombrero, pero se contempla valiéndose de su espejito; Viana anda siempre cámara en ristre para conservar grabada a Inés; el narrador observa a través del velo de la miopía o por entre las rendijas de su sombrero; e Inés, quien parece prestarle escasa atención a los demás, se repasa el cuerpo con las gafas y el espejo (p. 85). En cambio, a la hora de la verdad, de la confesión en la piscina, los dos hombres hablan cara a cara, sin mediación alguna (p. 89).

El autor ha logrado singularizar perfectamente a los personajes, siempre en consonancia con las escenas, como si de una representación teatral o del guión de una película se tratara, pues a veces nos proporciona una doble descripción de alguno de ellos, primero en bańador y posteriormente vestido, como ocurre con Viana, e incluso con el mismo narrador. En la primera escena, en la playa, casi todos aparecen tocados: Luisa y el narrador con sus correspondientes gorros de paja, el nińo latoso con un gorro de marinerito, mientras que Viana solo lleva el casco negro y las correas sueltas en la desmesurada Harley-Davidson que conduce. Del narrador no sabemos demasiado, únicamente su miopía y que viste unos mocasines negros, sin calcetines, y pantalones blancos (p. 90). De Luisa, en cambio, se describe su rostro, «tallado y cándido y aún sin arrugas» (p. 80), pero sobre todo se destacan sus ojos, que - nos dice- «eran de color ciruela, con irisaciones», $\mathrm{y}$ "se movían, como si no pudieran acostumbrarse durante la noche a dejar de hacer lo que hacían durante el día» (p. 86, 87 y 104). El narrador también rememora en diversas ocasiones cómo duerme Luisa: desnuda pero envuelta en una sábana convertida en toga (p. 87, 88, 93 y 104).

Sin embargo, a quienes llegamos a conocer mejor es a la desigual pareja de novios. Así, la joven y adorada Inés, tiene 23 años, no solo es objeto de un minucioso retrato, sino también se detallan sus movimientos:

Ella era hermosa, indolente, pasiva, de carácter extenuado (...), apenas si se movía, y desde luego no se ocupaba de nada que no fuera su propio embellecimiento y aseo. Dormitaba, en todo caso solía estar tumbada y con los ojos cerrados, boca arriba, boca abajo, de un costado, del otro, untada de cremas, brillante, los brazos y las piernas siempre extendidos para que no dejaran de broncearse los pliegues de la piel, ni las axilas, ni aun las ingles (ni por supuesto las nalgas), pues su braguita era minúscula y las dejaba al descubierto sin que asomara lateralmente el menor rastro de vello, lo cual hacía pensar (...) en un previo afeitado pélvico. De vez en cuando se incorporaba o sentaba, y entonces se quedaba largo rato con las piernas encogidas mientras se esmaltaba o pulía las uńas o, con un pequeño espejo en la mano, se buscaba en el rostro 
o los hombros imperfecciones cutáneas o alguna traza pilosa indeseada. Era curioso ver cómo aplicaba el espejo a las partes de cuerpo más inverosímiles (...), no sólo a los hombros, digo, sino a los codos, a las pantorrillas, a las caderas, a los pechos, al interior de los muslos, también al ombligo. (p. 82)

A este exhaustivo retrato propio de otro adorador más de Inés, sigue una digresión sobre su belleza, algo que resulta singular porque Marías ha contado que no suele utilizar nunca esa palabra ${ }^{14}$. Una vez que conocemos la historia de Inés contada por Viana, no podemos dejar de pensar que el personaje tiene algo de Lolita, aunque lo sea de una manera atípica, y desde luego se nos muestre ya crecida. Recuérdese que para Marías, en la novela de Nabokov, una de sus preferidas, se relata «la historia de una fidelidad, tan dura como melancólica, como lírica» ${ }^{15}$. En cambio, el cuento del que ahora nos ocupamos se centra en «el espectáculo de la adoración», una veneración inmutable y excesiva, según Viana, tampoco ajena a la novela del escritor ruso (p. 81 y 95-101), espectáculo presente también en otro cuento de Marías, "Todo mal vuelve», en donde el narrador comenta que «el espectáculo de la adoración no es nunca agradable de contemplar» (p. 180). En ambos relatos son los hombres, Viana y Xavier Comella, los adoradores desmedidos. Este sentimiento -se comenta-empezó muy pronto: cuando Inés tenía 7 ańos, Viana 39 y Xavier 14. Sabemos que Viana, tarde o temprano, no tendrá más remedio que asesinarla; mientras que el empalagoso Comella, quien padece una «depresión melancólica», acaba suicidándose, tras separarse y divorciarse de Éliane, su refinada esposa francochina.

14. Sobre la palabra belleza, vid. A veces un caballero, p. 357. Y continúa la descripción de Inés: «[De] su belleza sería fácil decir que era convencional, pero resultaría una definición pobre o demasiado amplia o vaga. Se trataba más bien de una belleza irreal, lo cual, en este caso, quiere decir lo mismo que ideal. Era la belleza en la que piensan los niños, que es casi siempre (excepto en los ya desviados) una belleza pulcra, sin ninguna arista, en reposo, mansa, privada de gestos, de piel muy blanca y pecho muy grande, ojos redondos -no rasgados al menos- y labios idénticos (...): una belleza de dibujos animados o, si se prefiere, de anuncio (...), de los que suelen verse en las farmacias, deliberadamente desprovisto de toda sensualidad para que no turben a las mujeres ni a los ancianos (...) En modo alguno era virginal, sin embargo, y aunque no quisiera decir que era una belleza lechosa, lo era, o si no cremosa, a la que le costaría adquirir un tono de piel moreno (su piel era brillante, pero no dorada), como el que tenía ya Luisa; era una belleza lisa, exuberante pero que no invitaba al tacto (aunque quizá vestida), como si anunciara derretirse a la menor presión, al menor contacto, como si hasta una caricia o un beso suave se fueran a tornar en ella violencia y ultraje» (p. 82 y 83; y puede completarse en las p. 84, 88 y 104, en las que se insiste en que Inés tiene una belleza «irreal» e «inmutable»).

15. Vid. «De memoria locuaz leída», A veces un caballero, p. 356. Sobre el interés de Marías por Nabokov y la influencia de Lolita en «Mientras ellas duermen», vid. los artículos de nuestro autor: "La novela más melancólica (Lolita recontada)», Literatura y fantasma, p. 327-336, y "Vladimir Nabokov en éxtasis", Vidas escritas, 2012, p. 111-120; el libro de Gareth Wood, Javier Marias's Debt to Translation Sterne, Browne, Nabokov, Oxford University Press, Oxford, 2012; y la entrevista digital, El Pais, 3 de marzo del 2010 (http://www.elpais.com/edigitales/entrevista. html?id=6346), donde la cita, junto a Luz de agosto y El guardián entre el centeno, como su novela preferida. 
De Alberto Viana conocemos que vive en Barcelona, es abogado especialista en divorcios y que tiene algo más de cincuenta años y unos ojos castańos (p. 94) ${ }^{16}$. Pero, sobre todo, se nos muestra su aspecto físico, su vestimenta e incluso alguno de sus gestos más característicos: «Era lo que se llama un gordo o incluso un gordo infame o también gordo seboso, y debía llevarle a la joven no menos de treinta ańos», calvo y con un bigote abundante y cuidado, que luego se afeitará. Por lo que se refiere a la vestimenta, en la playa lucía el mismo modelo de bańador bicolor, siempre tan pequeño y ceñido que parecía a punto de desgarrarse, pero cuyos originales colores cambiaban, aunque nunca lograra armonizarlos adecuadamente (p. 83, 90). Cuando se halla, en cambio, en la piscina del hotel, se comenta que su ropa resultaba fea y mal combinada: así alterna una camisa ancha con pantalones claros, mocasines -primero- rojos y más tarde, «rojo rabioso», y para escándalo del narrador, calcetines (p. 87, 89 y 96). No obstante, en la confesión final, Viana se justifica ante el narrador por el inadecuado vestuario que suele exhibir (p. 98). Pero es en la piscina donde el narrador puede observar con detenimiento sus gestos, la relación que guardan las manos, el rostro y la cabeza, y retratarlo a su antojo: «Tenía una cara afable, de ojos despiertos, sus facciones no eran feas, sólo gordas, me pareció que era un calvo guapo, como el actor Piccoli o el pianista Richter. Sin el bigote resultaba más joven, o tal vez eran los mocasines rojos...» (p. 89).

Entre los personajes se trenzan inevitables contrastes y semejanzas, tanto por lo que se refiere al aspecto físico de ambas mujeres, e incluso de los dos hombres, como por el papel que la conversación desempeña en todos ellos. El narrador, quien habla con su esposa, solo le cede la palabra a Viana; en cambio, a Inés no la oímos decir nada, apenas se comunica con su pareja; su presencia es meramente corporal, quizá porque solo sea eso: un cuerpo. Luisa se nos muestra con suma discreción y respeto, frente al detallado retrato de la joven. No menos significativa resulta la inmovilidad de Inés frente a la constante rotación de Viana, siempre cámara en ristre; o los bañadores igualmente escuetos que comparte la pareja de Barcelona, aunque con resultados y efectos bien distintos. Pero quizá lo más llamativo sea que el narrador acabe cosificándolos, pues Viana pronto será «un gordo o incluso un gordo infame o también gordo seboso» (p. 83, 84, 86, 94 y 95) e Inés el cuerpo (p. 86). Por tanto, las descripciones del narrador degradan a los personajes, lo que contrasta con la dignidad que le atribuye siempre a Luisa, e incluso la que deja traslucir de sí mismo. No hay más que comparar, por ejemplo, la vestimenta clásica del narrador con la mucho más atrevida y desconjuntada de Viana. Podría decirse, por tanto, que se condena a Inés y a su novio no solo por lo que nos cuenta sobre la relación que mantienen, sino también por su aspecto y conducta ${ }^{17}$.

16. Esa misma duplicidad de los protagonistas, el uno es de Madrid y el otro de Barcelona, aparece también en su cuento "Gualta».

17. El narrador se burla también del bañista inglés por su vestimenta inapropiada, por la camiseta verde («el estómago verde mojado», p. 81) que luce en la playa. Este procedimiento no es inhabitual en su obra, pues, recuérdese que, por ejemplo, Ruibérriz de Torres, personaje de "Sangre de lanza», Mañana en la batalla piensa en mí y Los enamoramientos, aparece caracterizado 
Se pone de manifiesto, además, el contraste y la antítesis entre dos atmósferas: la diurna, soleada y pública de la playa; y la nocturna y privada de la piscina, «el agua sin más reflejos que los astrales», presidida por la luna (aunque en esta ocasión el autor no recurra al adjetivo pulposa, o lechosa, habitual en él, cuyo origen se encuentra en el poema "Habitación de hotel», de Nabokov) ${ }^{18}$ envuelta en estricto silencio (p. 86-90, 94, 102 y 103). Marías ha afirmado, a propósito de Desde la isla, libro de su antiguo condiscípulo Eduardo Calvo, que en cualquier ficción aprecia tanto la atmósfera como las frases memorables, fogonazos o aforismos intercalados ${ }^{19}$.

El título del cuento remite a la situación fundamental de la trama, a lo que ocurrió durante el diálogo que mantienen Viana y el narrador, mientras se supone que Luisa e Inés duermen. Marías lo convierte, así, en un leitmotiv que se repite («Luisa dormía e Inés también dormiría», p. 88, 99, 101, 102 y 104); en el que parece hablar el narrador, con la duda del condicional cuando se refiere a la adorada. En suma, podría decirse que durante el descanso de las mujeres en sus respectivas habitaciones, "dormía el mundo, detenida su débil rueda» (p. 101), Viana pone al tanto al narrador de sus relaciones con la chica, y qué pretende seguir manteniendo. Pero conforme nos acercamos al final, siembra la duda sobre si realmente ambas mujeres siguen vivas (p. 103 y 104). No olvidemos que Marías ha confesado en más de una ocasión que suele titular sus textos cuando los ha acabado ${ }^{20}$.

En mi opinión, el desenlace genera una intriga no prevista por el lector. ¿̨Por qué abandona Viana su habitación durante la noche y se queda meditabundo junto a la piscina, "un poco ensimismado», con el rostro hundido entre las manos, como si estuviera abatido o tenso, hasta que llega el narrador? ¿Acaso ha matado Viana a su adorada Inés, posibilidad que él mismo le sugiere a su interlocutor? (pp. 88, 94 y 101). No lo sabemos a ciencia cierta. Por su parte, el narrador observa en compañía de Luisa, y luego atiende, oye, ahora junto al confidente. Así, podría decirse que pasa de observar la representación de la adoración a escuchar su historia, por lo que también el cuento podría leerse como la peripecia de un mirón que, en la tercera parte del mismo, se convierte en oyente, en interlocutor. Por este tipo de escenas, el profesor Rico, en la contestación al discurso de entrada en la Academia de la Lengua de nuestro autor, lo tachó de "gran mirón", como también suelen serlo sus personajes, quienes observan y escrutan sin parar. En cambio, en Literatura y fantasma,

por su hablar tosco y su inadecuada manera de vestir. Más digno, en cambio, lo encontramos en el cuento «Mala índole». Todo ello debería llamar la atención del lector, dado que en nuestro tiempo la permisividad en el vestir es absoluta, y las fronteras entre el buen y el mal gusto han desaparecido, o -para ser precisos- no resulta prudente aludir al asunto.

18. Cf. la entrevista de Domingo Ródenas de Moya, p. 46.

19. Vid. "Dieciséis años callando", A veces un caballero, p. 333. En nuestro cuento, en cambio, el narrador comenta con desdén que el bañista inglés «opinaba de continuo sobre la temperatura, la arena, el viento y las olas con tanto énfasis y grandilocuencia como si cada vez estuviera emitiendo una profunda máxima o aforismo largamente meditado» (p. 80).

20. Vid. «Bestiales», Mano de sombra, p. 114. 
comenta que hay personajes que tienen que "perseverar en su mirada», según ocurre en nuestro cuento, donde volvemos a encontrarnos con lo que Elide Pittarello considera «el eje de la narrativa de Javier Marías: la relación conflictiva entre el decir y el hacer y viceversa, un quiasmo fundado en la paradoja, cuyo haz de antinomias indecidibles la razón no alcanza» ${ }^{21}$.

Viana necesita que su «largo pensamiento» sea oído (p. 93), e incluso podría decirse que como ocurre en Otelo, vierte su pestilencia en el oído del narrador ${ }^{22}$. Aunque, al fin y a la postre, todo sea mera conjetura. El narrador no se conforma con observar, tiene que oír, escuchar las razones o sinrazones de Viana, aunque tampoco le basten para comprender, de ahí las nuevas preguntas que le va formulando mientras ellas duermen. Ahora bien, ¿duermen realmente? Luisa, sí, como sabremos en el desenlace, cuando reclama la atención de su marido desde la terraza de la habitación, rompiendo el silencio de la noche. Pero ¿̇igue durmiendo Inés en su habitación? ¿No habrá sido asesinada? Si creemos lo que dice Viana, hemos de pensar que está viva, descansando, pues le ha contado al narrador que al día siguiente se acaban las vacaciones y regresan a Barcelona. Y, no obstante, la duda ya ha sido sembrada. Recuérdese, además, que el relato se inicia con el narrador titubeando acerca de si volverá a ver de nuevo a Inés ${ }^{23}$.

El caso es que leyendo la confesión de Viana, la cual podría entenderse como una larga digresión mientras ellas duermen, he recordado el comentario de Marías a propósito de las historias orales y escritas de Guillermo Cabrera Infante, lo que él denominaba sus cuentos, quien como el narrador persuasivo que era no solía considerar los conceptos de fundamento o verosimilitud, pues sus historias formaban parte de lo que nuestro autor denomina opinión narrativa o narración comentada, logrando así que la digresión se imbrique en la historia que se está contando, técnica que utilizaron con fortuna escritores tan libérrimos como Montaigne, Cervantes o Laurence Sterne ${ }^{24}$.

El cuento aprovecha diversos elementos que tienen su origen en una situación real, aunque todo lo que se narra en esencia sea fabulación. La misteriosa dedicatoria, «Para Daniella Pittarello, / por sus tantos conocimientos útiles», quizás apunte a alguna de las claves del origen de la narración. Pues dichas habilidades las comparte con el personaje de Luisa, de quien se pondera

21. Vid. Rico, p. 46; Literatura y fantasma, p. 169; y Pittarello, «Contar con el miedo», p. 13.

22. Una alusión semejante aparece también en Tu rostro mañana. 2. Baile y sueño, p. 108. Vid., además, la nota siguiente.

23. En otro de sus cuentos, "Prismáticos rotos», nos encontramos con una situación semejante. El narrador conoce por azar en el hipódromo de Madrid al guardaespaldas, o escolta, de un banquero rico. Éste, quien viste con tan poco gusto como ostentación, le confiesa que -aunque no lo desea- probablemente tendrá que matar a su jefe. Las preguntas que se hace el narrador, y quizá también los lectores, son semejantes: ¿por qué se confiesa? ¿matará realmente a quien le paga por protegerlo? El desenlace abierto nos impide saber qué ocurrirá, aunque todo apunta a que el asesinato se lleve a cabo. En esta ocasión, sin embargo, Marías oxigena el final, le proporciona un leve toque de humor, dejando que sea el narrador quien cobre la apuesta, a pesar de ser el guardaespaldas, que apenas nada sabía de caballos, el que acierte con la combinación ganadora de la carrera.

24. Vid. Literatura y fantasma, p. 269. 
«que sabe las cosas más raras e insignificantes y siempre me sorprende con sus conocimientos útiles». Como, por ejemplo, la posibilidad de observar sin ser observado, dada la miopía del narrador protagonista, rasgo este que comparte con el autor, a través del sombrero de paja ${ }^{25}$.

Podría afirmarse, además, que se trata de un cuento quijotesco, cervantino, pues al fin y a la postre se centra en «la historia del deseo de ser otro del que se es (y de su logro), y de la imposición por parte de los demás de que cada uno sea alguien, verdadero o falso, pero sólo uno ${ }^{26}$. En cualquier caso, su grandeza estriba en que resulta memorable por su atmósfera, la voz del narrador, sus preguntas, el tono de la confesión de Viana, con los correspondientes matices y recovecos, las escenas en la playa y en la piscina del hotel, el sombrero de paja que Luisa le cede al narrador para que pueda observar a los bañistas con disimulo, el hombre que graba incesantemente a su pareja, los movimientos y operaciones de Inés por mantenerse en perfecto estado de revista; y luego, en la piscina, gracias al silencio, la luna, el pie encalcetinado, el calcetín chorreante sobre la tumbona floreada; $y$, sobre todo, el futuro que le espera, en suma, a esa pareja barcelonesa, al adorador y a su adorada. Así, podría afirmarse que en el cuento, a través de numerosos detalles, se nos muestra lo que hay más allá de la mera apariencia, de la piel de Inés, de su cuerpo, de la adoración tontorrona de Viana.

En el artículo «Vivir sin enterarse» afirma Javier Marías que «la vida consiste en gran medida en imaginarse, hacia el pasado y hacia el futuro ${ }^{27}$. En nuestro relato, Viana ha logrado construir el futuro, pero es consciente de que no podrá seguir haciéndolo, y lo que se figura de este tiempo por venir le produce tanta inquietud que no está dispuesto a que suceda, de ahí que más tarde o más temprano deba matar a Inés sin remedio. Pero ¿por qué tendrá que asesinarla? Pues porque, según le explica al narrador, no podría dejar de adorarla y eso se producirá en cuanto comience el envejecimiento de la joven. Por tanto, el tiempo corre en su contra. Su tragedia consiste en haber estado esperando siempre: antes, el logro, la dádiva, ahora la pérdida, la decadencia. Cada uno, nos dice, tiene su propia vida y no puede renunciar a ella, hasta el extremo de confesar que más allá de él no puede existir nada para Inés (pp. 100-102). En el desenlace de su artículo «Nuestra ventura» cita Marías una frase de Cervantes que podría aplicársele perfectamente a Viana: «Tú mismo te has forjado tu ventura», con la consiguiente desventura posterior ${ }^{28}$.

Las semejanzas de «Domingo de carne» con el cuento anterior son notables. Veamos. Durante unas vacaciones de verano, una estación «lenta y sin objetivo»,

25. Vid. «Novelas cifradas», Mano de sombra, p. 280-282.

26. Vid. «Nuestra ventura», Vida del fantasma, 1995, p. 122.

27. Vid. Demasiada nieve alrededor, p. 293.

28. Vid. Literatura y fantasma, p. 360. El director Wayne Wang está preparando una película basada en "Mientras ellas duermen» y es probable que el actor Colin Firth desempeñe el papel de Viana. En un artículo reciente, Marías nos proporciona nuevos datos sobre los avatares que ha sufrido dicha versión. Vid. "A favor de la ocultación natural», El País Semanal, 13 de julio del 2014, p. 86. 
a no ser que el fin sea perder el tiempo (p. 157), mientras su mujer descansa en la cama, el narrador, otro mirón, observa con unos prismáticos desde la terraza de su hotel cómo se produce el asesinato de un hombre que se rasca la espalda y la cintura en la playa de la Concha, en San Sebastián. Así, este relato podría leerse como una variante del mismo, aunque menos compleja, pues parte de un esquema parecido. En esta ocasión, el matrimonio está también de vacaciones; el marido observa a la gente que pulula por la playa -nińos, gordos y chicas, "carne joven y madura y vieja, carne de niño», una mujer de edad media con sombrero de paja, aunque no sea visivo (p. 155)- mientras que ella, Luisa se llama una vez más la esposa, se interesa por lo que ve el narrador, quien intenta centrar la atención en alguien en concreto, «la playa como un teatro» (p. 158); y se describe con detalle los movimientos y la vestimenta de la víctima, lo que puede ver de ella. En cambio, las diferencias, en esencia, son dos: observamos el crimen en directo, pero a través de los prismáticos del narrador, que hace el papel de la cámara de filmar en el cuento anterior; pero no se produce diálogo alguno, pues apenas oímos solo la voz de quien relata. Sabemos, eso sí, que el asesino ocupa la habitación de al lado del hotel, la de la derecha; pero ignoramos quién es, y por qué se lleva a cabo el asesinato. Sí conocemos por el contrario la reacción del vecino de la víctima en la playa, el hombre esbelto que tiritaba en falso, por capricho, de pie sobre la toalla, quien al ver caer junto a él a un hombre muerto «se quedó parado, ya sin frío» (id). Como ven, tampoco en esta ocasión prescinde Marías de los detalles, e introduce una novedad: el narrador consigue encontrar la misma visión de la playa que tiene su vecino, lo que le permite observar el crimen desde una posición privilegiada, ver sin ser visto.

En otro de sus cuentos, "Un sentido de camaradería», también encontramos una insólita confesión, la que Baringo Roy le hace al narrador, al coincidir por azar en una boda, cuya ceremonia abandonan antes de que concluya. Durante la conversación que entablan en la puerta de la iglesia, Baringo revela que la novia ha sido su amante, una fiera en la cama, y pretende que siga siéndolo. Y le pronostica, a modo de prueba, que cuando los novios abandonen el templo, a él lo tacha de imbécil en varias ocasiones, ella intercambiará una mirada de complicidad. El narrador prefiere no fijarse -por camaradería, nos dice-, aunque sospecha que tal cosa no ocurrirá. Los lectores, sin embargo, no pueden dejar de preguntarse de quién va a sentirse la esposa cómplice: ¿¿de Baringo o del flamante marido? No lo sabemos a ciencia cierta, pero tiendo a pensar que del esposo: el guapo primo de María, la mujer a quien el narrador ha acompańado en la boda, más que del fanfarrón que le confiesa sus deseos pasados complacidos. Sea como fuere, en esta ocasión no se contenta con ser un testigo pasivo, con transmitirnos la confesión, sino que aprovecha para sembrar la duda sobre lo que cuenta su interlocutor.

El penúltimo relato del que voy a ocuparme se titula «Mala índole», aunque un castizo lo hubiera llamado malas pulgas, mala baba o mala leche. Quizá podríamos tacharlo de cuento falsamente cinematográfico, a diferencia de Los dominios del lobo, tan influida por el cine que había visto su jovencísimo autor. Marías ha recordado, al respecto, que es rara la novela suya en que no 
aparezca una película mencionada o aludida, o que no haya alguna escena o pasaje deudor del cine, prendida para siempre en la memoria ${ }^{29}$. En él se cuenta un episodio de la existencia de Ruibérriz de Torres, cuando solo contaba 22 ańos, quien en veinticuatro horas pasa de trabajar como profesor de dicción e intérprete de español de Elvis Presley, durante el rodaje de una anodina película de Hollywood, donde es conocido como Roy Berry, a ser abandonado entre matones por el cantante y su partida en un garito cutre del D.F., corriendo peligro de muerte. Así las cosas, acaba convirtiéndose en verdugo, de modo que sorprende que estos peligrosos avatares ocurran sin sentido aparente, envuelto el narrador en un absurdo embrollo de machotes vanidosos. Se trata, por tanto, de un cuento sobre la servidumbre de la fama, la manera caprichosa en que gira la veleidosa rueda de la fortuna y acerca de lo gratuita que parece haberse vuelto la existencia, desde el momento en que casi todos nuestros actos resultan caprichosos.

Además, habría que llamar la atención sobre la huida, de la que tanto se habla en el largo discurso que inicia el relato, extendiéndose a través de casi cuatro páginas. Tras este arranque especulativo en torno a la venganza y al odio, que retoma el narrador durante el no menos extenso desenlace, pues se completa a lo largo de tres páginas, la trama comienza a desarrollarse. Podría decirse que el cuento arranca con un ritornello, "nadie sabe lo que es ser perseguido..." (pp. 271 y 313), que reaparece en la conclusión, y acaba con otro: «He matado a un hombre...» (pp. 313 y 314$)^{30}$. Pero, en concreto, se nos presenta el envés de una gran estrella del espectáculo, en este caso Elvis Presley, aunque no en su conocida faceta de cantante, sino en su papel ocasional de artista de cine. A este propósito, el narrador protagonista destaca, sobre todo, dos aspectos: la trastienda de una película disparatada y oportunista, en la que nadie está en su sitio ni cumple su función, ya se trate del director o de los actores, el guión o las mismas canciones; y las servidumbres absurdas de la fama. Pero el principal objetivo del relato estriba en desmentir la versión oficial de algunos hechos que sucedieron durante el rodaje de la anodina Fun in Acapulco (1963; Vacaciones en Acapulco); en particular, los referidos a la presencia de Elvis en México, siempre negados por la productora. Así, el testimonio del narrador, treinta años después, confirma que el cantante estuvo presente en el rodaje mexicano, que no lo sustituyó su doble, pues él lo acompañó, e incluso estuvo a punto de costarle la vida.

En suma, tanto las especulaciones iniciales y finales, como la historia, apuntan a un único objetivo: a la experiencia de la persecución, a las distintas posibilidades en que esta puede presentarse; $\mathrm{o}$ a las terroríficas sensaciones que padece el perseguido. Pues en realidad la verdadera película, la existencia con

29. Vid. «Todos los días llegan», Vida del fantasma. Cinco años más tenue, p. 163.

30. En el desenlace de "Mientras ellas duermen», durante la conversación nocturna, Viana encabeza sus frases, hasta en cuatro ocasiones, con un "quién le dice qué...», cuya función estriba en alimentar las dudas en el narrador sobre lo que pudiera haber acaecido, aunque éste afirma y explica en el párrafo final no haber creído las insinuaciones (p. 103 y 104). 
ribetes de ficción, no la experimenta durante el rodaje, sino en esa visita al garito mexicano en compañía de Elvis y de alguno de los parásitos que solían rodearlo. Y allí, en la atmósfera que se crea, y no en las canciones ni en el guión, es donde el lenguaje adquiere realmente importancia, en el decir y no decir del intérprete, que es quien tiene la palabra y corre el riesgo de pagar las consecuencias, y en cierta manera las paga, por el terror que debe padecer cuando, tras una larga espera, está a punto de ser asesinado y de ser perseguido con sańa, o mala leche, y en ese mismo sentido aparece utilizada la expresión en La Regenta, en boca de Petra, criada de la protagonista ${ }^{31}$.

El caso es que de haberse escrito este cuento antes que «Lo que dijo el mayordomo» podría haber adoptado su título y llamarse «Lo que dijo el intérprete español»; del mismo modo que otros relatos de Marías podrían haber utilizado dicha fórmula: «Lo que dijo Mr Bayo...» («La dimisión de Santiesteban»), «Lo que dijo el abogado...» («Mientras ellas duermen»), «Lo que dijo el escolta...» («Prismáticos rotos»), «Lo que dijo el fantasma...» ("Cuando fui mortal»), "Lo que dijo Xavier Comella...» («Todo mal vuelve»), «Lo que dijo el actor porno..." ("Menos escrúpulos») o "Lo que dijo el indiscreto...» ( UUn sentido de camaradería»). Pero quizá lo más curioso sea que quien fue contratado como profesor de dicción no logre cumplir nunca con su cometido, limitándose -en cambio- a servirle a Elvis de intérprete, ni tampoco siquiera en el rodaje; sino solo durante ese descenso a los infiernos del D.F. en forma de garito, con sus correspondientes matones de medio pelo ${ }^{32}$.

Ese aprecio por el detalle lo hallamos también en otro de sus primeros cuentos publicados, nunca citado hasta donde yo sé, anterior a la aparición de su primera novela. Se trata de «El viejo vasco-andaluz»" ${ }^{33}$. El breve relato se compone de tres párrafos en los que el narrador, quien ha cumplido 92 ańos y vive recogido en un asilo de Huelva, cuenta en primera persona su relación con los Paredes, padre e hija, y la cena a la que lo invitaron seis o siete años atrás. Pero quizá su objetivo principal estribe en confesarnos sus deseos de seguir viviendo, para poder recordar. Esta temprana voz masculina en primera persona se halla presente en casi todas sus narraciones posteriores; junto con la idea del pasado como un refugio que puede ser reconfortante, pues allí nos encontramos a salvo, al percibirlo bajo la forma de ficción. Pero, además, espacio y tiempo, el asilo y la vejez, desempeñan un papel principal, pues como Marías le comenta a Elide Pittarello «el espacio es lo que contiene

31. Cf. Leopoldo Alas 'Clarín’, La Regenta, Crítica, Barcelona, 2006, p. 974. Ed. de Sergio Beser, José Luis Gómez y Rebeca Martín.

32. Una vez entregado este artículo para su publicación, la profesora Amélie Florenchie ha tenido la amabilidad de llamarme la atención sobre un trabajo que desconocía dedicado a «Mala índole», sobre todo a las relaciones entre cine y literatura, obra de Emmanuel Le Vagueresse, que por su interés debe consultarse, pues además incluye fragmentos de la correspondencia que mantuvo con Javier Marías, a propósito de algunos aspectos de esta obra.

33. Se publicó en El Noticiero Universal, el 14 de mayo de 1968, p. 8. Debo su descubrimiento a la generosidad de Pedro Arozamena, admirador de la obra de Marías, a quien agradezco que me haya enviado una copia del cuento. 
el tiempo y (...) la memoria depende en gran medida también del espacio» ${ }^{34}$.

El relato empieza presentándonos la situación y los personajes. Del señor Paredes se dice que cuenta con más de ochenta años, ha sido zapatero, y ocupa en el asilo la habitación contigua a la del narrador. De su hija sabemos que vive en un hospital y tiene más de cincuenta años, pero ha obtenido una semana de permiso para poder visitar a su progenitor. Durante esos días es cuando se produce la invitación. La cena, «muy decorosa», recuerda el narrador, «aquella velada tan modesta y tan opulenta a un mismo tiempo», "uno de mis últimos recuerdos placenteros», se describe con todo tipo de detalles: así, no sólo se nos dice qué comen (jamón, queso, vino, alimentos prohibidos para el narrador, y se fuma un puro durante la sobremesa), sino también de qué hablan padre e hija mientras el narrador los observa («toros, vecinos, el hospital, los viejos tiempos»), y finalmente qué habría querido decir él mismo, pero no dijo: «A mí me hubiera gustado hablar de Vizcaya, de Pío Baroja y de la veracidad de sus libros de marinos y aventuras» ${ }^{35}$. Por último, el anciano narrador confiesa estar mal («mi situación actual es bastante deprimente y mi condición baja»), aunque desea seguir viviendo, sobre todo para poder recordar tiempos mejores, "para pensar en Pío Baroja y en Bilbao, y para saber si lo que hice me sirvió, y para recordarme de vez en cuando a mí mismo que fui más de lo que soy ahora, en este asilo de Huelva». Además, le gusta rememorar su amor por la lectura, el haber tenido «un cierto postín, una cierta clase» y el orgullo que sentía por la admiración que le profesaba su ama de llaves. En suma, el grato recuerdo de una cena ocurrida hace unos pocos ańos empuja al anciano narrador a evocar momentos agradables de su vida pasada. De lo que nos cuenta se deduce que procede de Bilbao, aunque ahora se halle en el otro extremo de la Península, en Huelva, de ahí el título del relato. Pero lo que llama la atención es que el narrador se encuentre, por edad y experiencia vital, en las antípodas del autor. En su artículo "Autobiografía y ficción»", Marías reflexiona sobre las tentaciones más peligrosas en las que puede caer un escritor que empieza, entre las cuales tal vez sea la autobiográfica la más frecuente y peligrosa. No sabemos si el material de este cuento es verídico o incluso verdadero, aunque tiene más pinta de ser inventado, pero lo que resulta evidente es que nada guarda relación con su vida personal, aunque sí quizá con alguna historia oída o leída, o con una proyección de sí mismo en la vejez. Recuérdese, además, que tres años después, en 1971, cuando el autor cuente solo con 19 años, aparecerá su primera novela, Los dominios del lobo, en la que también consigue sortear con éxito estas mismas tentaciones.

Sabemos que para Javier Marías escribir es siempre un camino para averiguar algo, un modo de conocer los resortes que activan la conducta humana. De

34. Vid. Marías, «Un refugio confortable», 2013; y Pittarello, 2005, p. 12 y 22.

35. Sin embargo, respecto a los detalles, en una entrevista reciente, Marías precisa: "Casi nunca pongo detalles visuales de calles, paisajes, lugares (en la actual época, tan visual, no hace falta)», Octavio Vinces, Buen salvaje, p. 18.

36. Vid. «Autobiografía y ficción», Literatura y fantasma, 2001, p. 73-79. 
forma semejante a como ocurre en sus novelas, en la narrativa breve convive la especulación y la trama, el discurso y la historia. Los mismos personajes aparecen de continuo en otros relatos, o en sus novelas, en un viaje de ida y vuelta. Pero, sobre todo, llaman la atención los diversos narradores, a menudo observadores de hechos sorprendentes que nos relatan cuanto les dijeron, o que han vivido algo que solo logran comprender tiempo después, más allá de lo esperado o previsto.

En el caso de que existiera un relato tipo de Javier Marías, el narrador sería siempre alguien ansioso por transmitir la peripecia que ha oído, a veces por puro azar, o que le han contado previamente. En ellos predomina, por tanto, la historia, que transcurre entre lo acaecido y lo posible. El estilo no resulta aquí menos errabundo que en sus novelas, ni tampoco faltan los retratos precisos de personajes, los llamados miramientos. Los comienzos y finales tienden a ser singulares, y a veces se conectan, aunque en los relatos de misterio el enigma solo se desvele a medias, o se duplique en el desenlace. En suma, podría decirse que sus cuentos, más que ser hijos de sus novelas, tal como comentaba Cortázar sobre los de Henry James, comparten el mismo mundo narrativo ${ }^{37}$.

Sea como fuere, resulta indudable que su interés por el relato, ya sea en calidad de prologuista, mero lector, traductor o cultivador del artículo, ha sido constante. No en vano, lo primero que publicó fueron cuentos, y el último libro suyo que ha visto la luz es Mala indole. Cuentos aceptados y aceptables. Se ha ocupado, además, de la narrativa breve de Thomas Hardy, Isak Dinesen (su preferida), Nabokov o Salinger, mostrando siempre devoción por los cuentos de terror o de fantasmas, y en la actualidad por las piezas de Alice Munro (su candidata constante para el Premio Nobel de literatura, quien acaba de obtenerlo en 2013). A ellos habría que sumar, entre sus escritores de cuentos favoritos, narradores como Poe, Henry James, el escritor de relatos de fantasmas M.R. James, Maupassant, Chéjov, Conrad, Kipling, Chesterton o Faulkner $^{38}$. A Una belleza rusa y otras historias (Anagrama, Barcelona, 1992), de Nabokov, le dedicó Marías una modélica reseña en la que, además de alabar la traducción de Rafael Ruiz de la Cuesta, afirmaba que es «una de las obras cuentísticas a la vez más clásicas e innovadoras». Destaca en él su riqueza de registros, "casi como si supiera que el cuento por excelencia es en realidad el de género", tesis que también ha defendido nuestro autor. Pero quizá lo más significativo sea la filiación que traza entre el narrador ruso y algunos maestros del relato posteriores, de tal forma que el cuento "Humo aletargado" parece presagiar a Salinger; "El seductor», con su desenlace que queda fuera de lo contado, a Carver; la zozobra demente y fría del extraordinario "Última Thule», a Bernhard; o bien la delicada chanza de «Solus Rex», a Dinesen. Pero,

37. En una carta dirigida al escritor mexicano Juan José Arreola, fechada el 20 de septiembre de 1954, Cortázar apunta que Henry James es un gran cuentista, pero que sus cuentos son siempre hijos de sus novelas. Vid. Julio Cortázar, Cartas 1937-1954, Alfaguara, Madrid, 2012, p. 550.

38. Vid. las entrevistas o crónicas de Gaviñas y Manrique Sabogal. 
sigue Marías, en sus historias de Nabokov también se proyectan las sombras de maestros antiguos: Chéjov en el patetismo irónico de "Un lance de honor», Conrad en la fiebre de "Terra Incógnita», Kafka en la crueldad asumida de «El Elfo Patata». Así, en un único párrafo de su reseña, Marías no sólo muestra la tradición que antecede al autor ruso y la larga estela que dejó con sus cuentos, sino que también nombra a casi todos sus narradores favoritos. Y cuando, en la conclusión, afirma que este "no se contenta, así pues, con asomarse a los géneros a modo de apoyatura y divertimento sino que una vez dentro de cada uno traza historias y dibuja personajes que parecen cruciales, como sucede en todos los cuentos que tardan en olvidarse», resulta difícil no pensar que está hablando de sus propios gustos ${ }^{39}$.

A pesar de que su cuento más reciente date del 2005 y de que en el prólogo a sus Cuentos aceptados y aceptables comente que quizá no vuelva más al género, a quienes hemos disfrutado de piezas tan memorables como "La canción de Lord Rendall» (1989), «Mientras ellas duermen» (1990), «Lo que dijo el mayordomo» (1990), "Cuando fui mortal» (1993), «Todo mal vuelve» (1994), «No más amores» (1995) o "Mala índole» (1996), nos queda esperar que incumpla una vez más su palabra. Los lectores atentos recordarán que cuando concluyó la trilogía Tu rostro mañana comentó que quizá no volvería a escribir; si bien tras la publicación de su última novela, Los enamoramientos, anunció un nuevo libro de cuentos. Confiemos en que no haya, pues, dos arrepentimientos $-\mathrm{o}$ rectificaciones-, sino tres ${ }^{40}$.

\section{Bibliografía}

AA.VV., Tres cuentos didácticos, Barcelona, La Gaya Ciencia, 1975. Incluye textos de Félix de Azúa, Vicente Molina Foix y Javier Marías.

Acín Ramón, «El cuento y sus medios de difusión», Lucanor, núm. 6, 1991, p. 67-82. Aguilar Andrea, «Javier Marías rescata y amplía su antología de Cuentos únicos», El País, 13 de junio del 2004, p. 42.

Andres-Suárez Irene, «Los cuentos de Javier Marías o las múltiples caras de la realidad», en Irene Andres-Suárez y Ana Casas, ed., Javier Marias, Madrid, Arco Libros, 2005, pp. 197-215. 300 p.

A.S.M. [Alfonso Sánchez Magro], Reseña, núm. 272, 1996. Reseña de Cuando fui mortal.

Bértolo Constantino, «Realismo de almas», El País, 22 de abril de 1990. Reseńa de Mientras ellas duermen.

Castilla Amelia, «Javier Marías resume en Cuando fui mortal su producción cuentística de los últimos cinco ańos», El País, 13 de febrero de 1996.

39. Vid. «El canon Nabokov», Vida del fantasma. Cinco años más tenue, p. 436-438. La reseña se publicó primero en el diario El País. Libros, el 16 de enero de 1993, en unos años, los primeros noventa, en los que Marías dedicó mucha energía al cuento.

40. Gracias a Elide Pittarello, Amélie Florenchie, Javier Marías, José María Pozuelo Yvancos, Alexis Grohmann, Pedro Arozamena y Gemma Pellicer por la ayuda que me han prestado. 
Castillo David, y Marta Ciércoles, "Avui dia els escriptors hem renunciat a explicar-ho tot" ", Avui, 21 de marzo de 1996, p. VIII y X. Entrevista.

Cortázar Julio, Cartas 1937-1954, Madrid, Alfaguara, 2012, vol. 1. Ed. de Aurora Bernárdez y Carles Álvarez Garriga. 592 p.

Entrevista digital con Javier Marías, El País, 3 de marzo del 2010 (http://www.elpais. com/edigitales/entrevista.html?id=6346).

Gafarot Xavier, "Escribir debe ser una manera de averiguar algo" ", Diario 16, 27 de julio de 1994. Entrevista.

Gaviñas Susana, «Wayne Wang llevará al cine Mientras ellas duermen, de Javier Marías», $A B C, 10$ de octubre del 2012.

Goñi Javier, "Coherencia de escritor», El Mundo, 29 de abril de 1990. Reseña de Mientras ellas duermen.

Guardia $\mathrm{M}^{\mathrm{a}}$. Asunción, "No creo en los fantasmas pero ayudan a contar"», La Vanguardia, 20 de junio de 1997. Entrevista.

Hardy Thomas, El brazo marchito y otros relatos, Madrid, Reino de Redonda, 2004. Prólogo de Manuel Rodríguez Rivero. Traducción de Javier Marías.

Izquierdo Luis, «Una aproximación a los relatos de Javier Marías», Ínsula, núm. 568, abril de 1994, p. 19-21.

Le Vagueresse Emmanuel, "Javier Marías, un romancier postmoderne ?», en VVAA., Hommage à Carlos Serrano, Éditions hispaniques, Paris, 2005, p. 267-275.

— «Roman et cinéma dans "Mala índole" (1988) de Javier Marías : Elvis à Acapulco, ou Entre réel et fiction, une histoire de doubl(ur)es», en M.-M. Gladieu y A. Trouvé, eds., Voir et entendre par le roman, Epure, Reims, 2010, p. 77-99.

Manrique Sabogal Winston, "Entre el cuento y el olimpo literario», El País, 11 de octubre del 2012, p. 39.

Marías Javier, «El viejo vasco-andaluz», El Noticiero Universal (Barcelona), 14 de mayo de 1968 , p. 8.

- Los dominios del lobo, Edhasa (El puente literario), Barcelona, 1971; Anagrama, Barcelona, 1996. Prólogo del autor; Alfaguara, Madrid, 1999. Con prólogo y epílogo del autor. 338 p.

- y otros, Tres cuentos didácticos, Barcelona, La Gaya Ciencia, 1975.

- ed., Cuentos únicos, Madrid, Siruela, 1989. 279 p.; Reino de Redonda, Madrid, 2004 (ampliada).

- Mientras ellas duermen, Barcelona, Anagrama, 1990. 220 pp.; Madrid, Alfaguara, 2000 (ampliada). 244 pp.; Barcelona, Random House Mondadori (Debolsillo), 2007. Prólogo de Elide Pittarello, pp. 7-11. 186 p.

— «Quién escribe?», en Marina Mayoral, ed., El personaje novelesco, Madrid, Cátedra/ Ministerio de Cultura, 1990a, p. 91-99.

- prólogo a Isak Dinesen, Últimos cuentos, Madrid, Debate, 1990b, p. V-XII.

— «El cuento en España. Javier Marías», Leer, núm. 30, abril de 1990c, p. 40.

— «Falsificaciones literarias», Pasiones pasadas, Barcelona, Anagrama, 1991, p. 183188 [Sobre sus traducciones de los cuentos de Salinger].

- Vidas escritas, Madrid, Siruela, 1992. 175 pp.; Madrid, Alfaguara, 2012. Edición ampliada. 286 p.

- "Domingo de carne», El Correo Español-El Pueblo Vasco (Bilbao) y Diario Vasco (San Sebastián), 30 de agosto de 1992. Recogido en Cuando fui mortal, Madrid, Alfaguara, 1996. 241 p.; Barcelona, Random House Mondadori (Debolsillo), 2006. Prólogo de Elide Pittarello, pp. 7-10. 161 p. 
- Literatura y fantasma, Madrid, Siruela, 1993. 291 p.; Madrid, Alfaguara, 2001 (ampliada). 470 p.

- Vida del fantasma, Madrid, El País/Aguilar, 1995. 460 p.; Vida del fantasma. Cinco años más tenue, Madrid, Alfaguara, 2001 (ampliada).

— «Mala índole», El País, 19-24 de agosto de 1996; Mala indole, Barcelona, Plaza \& Janés, 1998.

- Mano de sombra, Madrid, Alfaguara, 1997. 333 p.

— "Un sentido de camaradería», El País Semanal, 2 de enero del 2000.

- A veces un caballero, Madrid, Alfaguara, 2001. 398 p.

- prólogo a Isak Dinesen, Ehrengard, Barcelona, Reino de Redonda, 2001, pp. 9-19.

- Tu rostro mañana. 2. Baile y sueño, Madrid, Alfaguara, 2004. 410 p.

- Donde todo ha sucedido. Al salir del cine, Barcelona, Galaxia Gutenberg/Círculo de Lectores, 2005. Prólogo de Miguel Marías. Ed. de Inés Blanca y Reyes Pinzás. $281 \mathrm{p}$.

- Corazón tan blanco, Barcelona, Anagrama, 1992.301 p.; Crítica (Clásicos y modernos, 12), Barcelona, 2006. Ed. de Elide Pittarello. 397 p.

- Demasiada nieve alrededor, Madrid, Alfaguara, 2007. 305 p.

- Mala indole. Cuentos aceptados y aceptables, Madrid, Alfaguara, 2012. 432 p.

— «Un refugio confortable», Jot Down, núm. 3, marzo del 2013.

Martín, Rebeca, "La destrucción de la biografía. El motivo del doble en dos cuentos de Javier Marías», en Irene Andres-Suárez y Ana Casas, ed., Javier Marias, Madrid, Arco Libros, 2005, pp. 231-241 [Sobre «Gualta» y «La canción de Lord Rendall»].

— "Penetrar en el reino de la incoherencia": la poética del cuento en Javier Marías», Ínsula, núms. 785-786, mayo y junio del 2012, p. 37-40. Monográfico dedicado al autor.

Martín Nogales, José Luis, «El cuento español actual», Lucanor, núm. 11, 1994, p. 43-67.

— «Evolución del cuento fantástico español», Lucanor, núm. 14, mayo de 1997, p. 11-21.

— "Tendencias del cuento español de los años noventa», en José Romera Castillo y Francisco Gutiérrez Carbajo, eds., El cuento en la década de los noventa, Madrid, Visor, 2001, p. 35-45.

— «Creación, mercado y lectores del relato actual», en Salvador Montesa, ed., Novelistas en el siglo XXI. Creación mercado y lectores, Málaga, Publicaciones del Congreso de Literatura Espańola Contemporánea, 2005, p. 69-79.

Masoliver Ródenas Juan Antonio, «Ideología de la decadencia», La Vanguardia, 9 de septiembre de 1976 [Sobre Tres cuentos didácticos].

Molero Alicia, «El narrador psicológico de Javier Marías», en José Romera Castillo y Francisco Gutiérrez Carbajo, eds., El cuento en la década de los noventa, Madrid, Visor, 2001, p. 257-266.

Ortega Carlos, «Ironías», Diario 16, 10 de mayo de 1990. Reseña de Mientras ellas duermen.

Pérez Gracia César, «Los relatos de Javier Marías», Archipiélago, núm. 6, 1991, p. 151 152. Reseña de Mientras ellas duermen.

Pittarello Elide, Rassegna Iberistica, núm. 57, junio de 1996, p. 66-68. Reseña de Cuando fui mortal.

- Entrevistos. Javier Marías, RqueR, Barcelona, 2005. 79 p.

— «Contar con el miedo», Ínsula, núms. 785-786, mayo y junio del 2012, p. 11-17. 
Pozuelo José María, Figuraciones del yo en la narrativa: Javier Marías y Enrique VilaMatas, Valladolid, Cátedra Miguel Delibes, 2010. 231 p.

— «Territorio Marías», ABC Cultural, 8 de diciembre del 2012, p. 10 y 11 [Sobre Mala indole. Cuentos aceptados y aceptables].

Rico, Francisco, Contestación al discurso de entrada a la Academia de Javier Marias. 55 p. Disponible en: http://www.rae.es/sites/default/files/Discurso_Ingreso_Javier_ Marias.pdf

Ródenas de Moya Domingo, «Los riesgos y rasgos del contar. Una conversación con Javier Marías», Insula, 785-786, mayo-junio del 2012, pp. 48 y 44-47. Monográfico dedicado al autor, coordinado por Alexis Grohmann y el autor de la entrevista.

Turpin Enrique, "La sutil omnisciencia del fantasma: "Cuando fui mortal”, de Javier Marías», La nueva literatura hispánica (Valladolid), núm. 2, 1998, p. 127-142.

Valls Fernando, «El renacimiento del cuento en España (1975-1993)», Son cuentos. Antología del relato breve español, 1975-1993, Espasa Calpe (Austral, 326), 1993, p. 9-78.

— "Lo que dijo el mayordomo”, de Javier Marías, o la disolución de los géneros literarios narrativos», en Irene Andres-Suárez, ed., Mestizaje y disolución de géneros en la narrativa hispánica contemporánea, Madrid, Verbum, 1998, p. 168-173.

— «Un estado de crueldad o el opio del tiempo: los fantasmas de Javier Marías», en Jaume Pont, ed., Brujas, demonios y fantasmas en la literatura fantástica hispánica, Lérida, Universidad de Lérida, 1999, p. 361-367.

- «نHa llegado Mondrian a la literatura? Los Aliocha Coll de Javier Marías», El pensamiento literario de Javier Marías, Amsterdam/Nueva York, Rodopi,. Monográfico de la revista Foro hispánico, núm. 20, 2001, p. 77-84. Recogido en mi libro La realidad inventada. Análisis critico de la novela española actual, Crítica, Barcelona, 2003, p. 134-144.

— «Arte del detalle», El País. Babelia, 20 de octubre del 2012, p. 8 [Sobre Mala índole. Cuentos aceptados y aceptables].

Vargas Llosa Mario, «Lolita cumple treinta años», prólogo a Vladimir Nabokov, Lolita, Barcelona, Círculo de Lectores, 1994, p. 9-17.

— «Los cuentos de la baronesa», prólogo a Isak Dinesen, Siete cuentos góticos, Barcelona, Círculo de Lectores, 2003, p. 9-18.

Vinces Octavio, «Javier Marías ante siete cuestiones fantasmales», Buen salvaje (Lima), núm. 3, enero-febrero del 2013, p. 18-20. 